\title{
Structure Based Innovative Approach to Analyze Aptaprobe-GPC3 Complexes in Hepatocellular Carcinoma
}

\section{Woo-Ri Shin}

Chungbuk National University

\section{Dae-Young Park}

Chungbuk National University

Ji Hun Kim

Korea Advanced Institute of Science and Technology

Jin-Pyo Lee

Chungbuk National University

Nguyen Quang Thai

Chungbuk National University

In-Hwan Oh

Chungbuk National University

\section{Simranjeet Singh Sekhon}

Chungbuk National University

\section{Wooil Choi}

Jeonbuk: Jeonbuk National University

\section{Sung Yeon Kim}

Wonkwang University

\section{Byung-Kwan Cho}

Korea Advanced Institute of Science and Technology

\section{Sun Chang Kim}

Korea Advanced Institute of Science and Technology

Jiho Min

Jeonbuk: Jeonbuk National University

Ji-Young Ahn ( $\sim$ jyahn@chungbuk.ac.kr)

Chungbuk National University https://orcid.org/0000-0002-3729-2284

\section{Yang-Hoon Kim}

Chungbuk National University

\section{Research}


Keywords: Glypican-3, Hepatocellular Carcinoma, Cancer diagnosis, Aptaprobe, Structure-based molecular interaction, Aptablotting, ALISA, Aptatoptical imaging

Posted Date: January 3rd, 2022

DOI: https://doi.org/10.21203/rs.3.rs-1197761/v1

License: (c) (1) This work is licensed under a Creative Commons Attribution 4.0 International License. Read Full License 


\section{Abstract}

Background Glypican-3 (GPC3), a membrane-bound heparan sulfate proteoglycan, is a biomarker of hepatocellular carcinoma (HCC) progression. Aptamers specifically binding to target biomolecules have recently emerged as clinical disease diagnosis targets. Here, we describe 3D structure-based aptaprobe platforms for detecting GPC3, such as aptablotting, aptaprobe-based sandwich assay (ALISA), and aptaoptical imaging analysis.

Results For preparing the aptaprobe-GPC3 platforms, we obtained 12 high affinity aptamer candidates (GPC3_1 to GPC3_12) that specifically bind to target GPC3 molecules. Structure-based molecular interactions identified distinct aptatopic residues responsible for binding to the paratopic nucleotide sequences (nt-paratope) of GPC3 aptaprobes. Sandwichable and overlapped aptaprobes were selected through structural analysis. The aptaprobe specificity for using in HCC diagnostics were verified through Aptablotting and ALISA. Moreover, Aptaoptical imaging showed that the binding property of GPC3_3 and their GPC3 specificity were maintained in HCC xenograft models, which may indicate a new HCC imaging diagnosis.

Conclusion Aptaprobe has the potential to be used as an affinity reagent to detect the target in vivo and in vitro diagnosing system.

\section{Introduction}

Liver cancer is the fifth most common cancer and the second leading cause of cancer-related deaths worldwide [1]. Hepatocellular carcinoma (HCC) is the primary type of liver cancer, accounting for $85-90 \%$ cancers formed by liver cells [2]. Hepatitis B virus, hepatitis $\mathrm{C}$ virus, and alcoholic liver disease are responsible for most HCC cases $[3,4]$. Although current diagnostic tests and treatments for all cancer types have significant developments, the fatality rate for HCC remains very high. The mortality caused by $\mathrm{HCC}$ is increasing because early HCC stages are usually asymptomatic. When it causes symptoms, it is already at an advanced stage, causing difficulties in treatment [5]. As researchers learn about the mechanisms of HCC, new diagnostic tools are constantly being developed. Biomarkers and imaging studies are commonly used to diagnose HCC. Numerous serum biomarkers are used for diagnosing HCC, including a-fetoprotein (AFP), lipocalin 2 (LCN2), osteopontin (OPN), des-y-carboxy prothrombin (DCP), and a fucosylated AFP glycoprotein variant (AFP-L3) [6-8]. In particular, AFP is a popular biomarker that has been extensively studied for HCC detection and diagnosis. With a $20 \mathrm{ng} / \mathrm{mL}$ cutoff value in serum, the observed serum AFP sensitivity for diagnosing HCC ranges from 60 to $80 \%[9,10]$. However, it dropped to $40 \%$ when it was used for detecting small tumors $(<3 \mathrm{~cm})$. On the contrary, serum AFP level $(20-200 \mathrm{ng} / \mathrm{mL})$ also increased in a significant number of patients with chronic liver diseases, including $15-58 \%$ patients with chronic hepatitis [11] and $11-47 \%$ patients with cirrhosis [12]. In fact, it is not uncommon to find high AFP levels in patients with cirrhosis or HCC and cirrhosis overlap, which causes confusion in assays using AFP biomarkers $[7,13]$. Thus, it is essential to identify a biochemical marker with better sensitivity and/or specificity than AFP for distinguishing HCC from benign liver lesions. 
GPC3 is one of six mammalian members of the glypican family (GPC1-GPC6) with heparan sulfate proteoglycans linked to the cell surface through a glycosyl-phosphatidylinositol (GPI) anchor $[14,15]$. GPC3 is essential in cell growth, motility, and differentiation, and plays an important role in regulating cancer cell proliferation through interactions with other growth factors [16, 17]. GPC3 protein is highly expressed in HCC, but not in cholangiocellular carcinoma, gallbladder cancer, or benign liver tissues. Thus, it may be a novel serological marker for the early detection of primary liver cancer, particularly HCC [18-20]. Using a human GPC3 protein-specific polyclonal antibody, it has been shown that GPC3 is expressed in up to 70\% HCC tumors, but not in normal liver tissues [21]. GPC3 has also been found to be overexpressed in HCC cell lines, including HuH6, HepG2, PLC/PRF/5, Hep3B, HuH7, and HT17 [22]. A recent study showed that high GPC3 expression is not dependent on tumor size. In addition, it has a $56 \%$ sensitivity for patients with small early stage tumors [23]. A meta-analysis evaluated GPC3 use in early stage HCC detection (TNM stage I or BCLC 0 and A) and observed the specificity and sensitivity to be 97.0 and $55.1 \%$, respectively [24]. For comparison, the specificity and sensitivity of AFP in similar studies were about 87.6 and $34.7 \%$, respectively $[25,26]$.

Molecular probes are powerful tools for identifying disease biomarkers and tracking them in their native environments. SELEX technology has been developed as an in vitro selection method to screen aptamers, which are nucleic acid ligands with prominent functionalities. Aptamers are short single-stranded nucleic acid oligomers (ssDNA, RNA, or amino acids) that can fold into or around a target [27-30]. In addition, aptamers can bind to their targets (nanomolar to picomolar range) with high affinity and specificity and display low to no immunogenicity. They are smaller than antibodies; hence, they are easy to synthesize and chemically modify. Recently, numerous benefits of aptamers as antibody alternatives have been intensively studied for a wide range of applications, such as diagnosis and therapeutic agents like aptaprobe. Aptaprobe is a functionalized-enhanced aptamer for target detection, used as an oligorecognition molecule in diagnostic platforms for wide array of clinical samples, including blood, urine, and saliva. Reportedly, the aptamer binds to target molecules through its specific shape by a 3dimensional (3D) structure of the sequence [31-33]. Understanding the interaction between the aptaprobe and its target molecules is a key step in improving aptaprobe-based diagnostic platform technology [28]. In this study, we performed 3D structure-based molecular docking simulations, which were applied to predict the 3D aptaprobe binding structure, followed by validation using in vitro GPC3 detection. Our structure-based simulation study has the following three standpoints: (i) it can provide problem-solving strategies for understanding the 3D structure of aptaprobes, (ii) aptaprobe-binding mechanism on the biological key sites can provide specific local features, including the improvement of aptaprobe-binding strengths and weaknesses without actual tests, and (iii) it provides virtual contact map prediction of intrachain nucleotide-amino acid residues for elucidating the detailed features and roles of the identified contact moieties.

The study includes three major stages: (i) aptamer screening explains the isolation technique of aptamer candidates, (ii) the aptaprobe and aptaprobe-GPC3 complex structural interaction, and (iii) technical platform validations; aptablotting, aptaprobe-based sandwich assay (ALISA), and Aptaoptical imaging analysis. The first stage has two components: in vitro SELEX and surface plasmon resonance (SPR) 
affinity analysis. The second stage describes in detail the 3D structural analysis of molecular interactions to provide specific aptaprobes. Next, the platform validation stage describes the experimental results showing the applicability of the selected aptaprobes, and concludes the study by summarizing the results and contributions of HCC-targeted specific diagnosis. The overall flow of this study is shown in Scheme 1 .

\section{Materials And Methods}

\subsection{Protein and buffer solutions}

The aptamers used in all the experiments were synthesized by IDT (Coralville Johnson County, IA, USA). Recombinant human glypican proteins (GPC3 and GPC5) were purchased from R\&D Systems (Minneapolis, MN, USA), and anti-human GPC3 monoclonal human antibody was purchased from G\&P Bioscience (Santa Clara, CA, USA). HSA, BSA, human serum, and anti-mouse IgG peroxidase were purchased from Sigma (St. Louis, MO, USA). Horseradish peroxidase (HRP)-conjugated streptavidin was purchased from Thermo Fisher Scientific (Minneapolis, MN, USA). The following buffers were used: TBST buffer $(0.1 \%(\mathrm{v} / \mathrm{v})$ Tween 20 in Tris-buffered saline, $\mathrm{pH} 7.2)$, blocking buffer ( $5 \%$ non-fat dried milk in TBS-T), and washing buffer (TBS-T buffer).

\subsection{Molecular docking structural analysis}

GPC3 aptamers were identified through a SELEX process; details of the selection can be found in the Supporting Information. The secondary structure of GPC3_1-GPC3_12 was obtained using the Mfold web server (http://mfold.albany.edu/?q=mfold) at $25^{\circ} \mathrm{C}$ in a $\left.250 \mathrm{mM} \mathrm{[Na}{ }^{+}\right]$folding algorithm based on nucleotide sequences. A 3D RNA model was constructed from the secondary structure predicted using the Mfold program [34]. The ssDNA structures of aptamers were built by converting RNA to DNA using Pymol software [35]. The amino acid sequence of GPC3 was obtained from UniProtKB/SwissProt (P51654.1), which was used to predict GPC3 protein structure using SWISS-MODEL (https://swissmodel.expasy.org/). The docking prediction of the GPC3 protein-aptamer complexes was analyzed using the MOE2016.08 program [36]. All GPC3 protein and aptamer 3D models were minimized using an energy minimization algorithm (gradient: 0.1, Force Field: Amber10: EHT). The Triangle Matcher method was used to analyze the GPC3 protein and aptamer binding region. The results of the interaction and distance between the GPC3 protein and aptamer were generated using Pymol, COCOMAPS/CONSRank [37], and LigPlot+ [38]. Finally, the GPC3-aptamer complex (GPC3_2, GPC3_3, and GPC3_9), named "aptaprobes," was structurally analyzed.

\subsection{Cell culture}

All cell lines, including HepG2 (ATCC HB-8065), Hep3B (ATCC HB-8064), PANC-1 (ATCC CRL-1469), MIAPaCa-2 (ATCC CRM-CRL-1420), and HeLa (ATCC CCL-2) were purchased from the American Type Culture Collection. All cells were cultured in Dulbecco's modified Eagle's medium (DMEM; Welgene, Gyeongsan, 
Korea) supplemented with 10\% (v/v) fetal bovine serum (FBS; Gibco, Minneapolis, MN, USA) and incubated at $37^{\circ} \mathrm{C}$ with $5 \% \mathrm{CO}_{2}$.

\section{4 mRNA expression test}

HCC cell lines [HepG2 (ATCC HB-8065), Hep3B (ATCC HB-8064)], pancreatic cancer cell lines [PANC-1 (ATCC CRL-1469), MIA-PaCa-2 (ATCC CRM-CRL-1420)], and HeLa cell line (ATCC CCL-2) were cultured on $100 \Phi$ dishes. RNA was extracted using the TRIzol ${ }^{\mathrm{TM}}$ Plus RNA Purification Kit (Thermo Fisher Scientific).

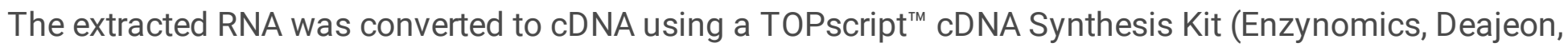
Korea). GAPDH and GPC3 genes were PCR-amplified using gene-specific primers [GAPDH (Forward: 5'GCTTTAGTTCGACAGTCAGCC-3', reverse: 5'-TTACATGGTT GAGCACAGGGT-3'), GPC3 (Forward: 5'TAATTTATGGCCGGGACCGTG-3', reverse: 5'-TCGAGTTCAGTG CACCAGGAA-3')]. PCR was performed for 25 cycles. The results were confirmed using $2 \%$ agarose gel electrophoresis.

\subsection{Cell viability and mitochondrial respiratory competency assay}

Cell viability and mitochondrial respiratory competency were determined by MTT assay and Seahorse XF analyzer mito stress test assay (Agilent Technologies, Santa Clara, CA, USA). For MTT assays, HepG2 cells were seeded in 48-well plates and incubated overnight for cell adhesion. They were then incubated for $24 \mathrm{~h}$ with 10-0.125 $\mathrm{MM}$ GPC3_3 aptaprobe (two-fold dilutions) and wells containing untreated cells were used as controls. At the end of incubation, the media was replaced with fresh media containing MTT and further incubated at $37^{\circ} \mathrm{C}$ for $4 \mathrm{~h}$. Finally, the formazan crystals were dissolved in dimethyl sulfoxide (DMSO) and the absorbance at $570 \mathrm{~nm}$ was recorded using a SPECTRAMAX M2e ELISA reader (Molecular Devices, San Jose, CA, USA). The Seahorse XF analyzer mito stress test assay was performed on HepG2 cells $\left(1.8 \times 10^{4}\right.$ cells/well) treated for $1 \mathrm{~h}$ with various GPC3_3 aptaprobe concentrations. The OCR and ECAR were measured before and after treating the cells with mitochondrial toxins oligomycin (ATP synthase inhibitor, $1.5 \mu \mathrm{M}$ ) and carbonyl cyanide-4-phenylhydrazone (FCCP, uncoupling agent, 0.5 $\mu \mathrm{M}$ ), and rotenone/antimycin $\mathrm{A}$ (Rot/AA, uncoupling agent, $0.5 \mu \mathrm{M}$ ) to determine the baseline and stress measures of oxidative phosphorylation and glycolysis, respectively. The OCR and ECAR values were normalized to the total protein concentration. All experiments relative to the control were expressed as the mean \pm standard error of mean (SEM) from at least triplicate studies.

\subsection{Confocal microscopy image and flow cytometry}

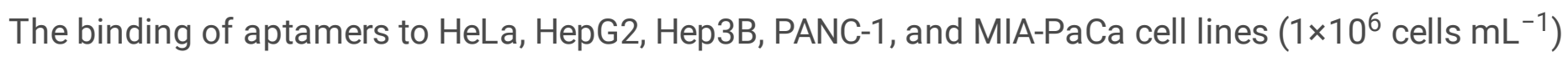
was monitored using confocal microscopy. After washing twice with cold washing buffer, the cells were incubated with FAM-labeled GPC3 aptaprobes (GPC3_3, GPC3_2, and GPC3_9) at 37² C for $1 \mathrm{~h}$.

Subsequently, the cells were washed twice, imaged using a Zeiss LSM 710 Upright confocal microscope (Oberkochen, Germany), and analyzed using a BD FACS Calibur ${ }^{\mathrm{TM}}$ Flow Cytometer (Franklin Lakes, NJ, USA).

\subsection{HCC xenograft model generation}


HCC xenograft models were created using HepG2 cells. Briefly, $1 \times 10^{7}$ cells were injected subcutaneously into the right flank of 6-week-old BALB/c nude mice (Orienbio, Seongnam, Korea). The tumor was allowed to grow till 100-200 $\mathrm{mm}^{3}$ (measured with a Vernier caliper). The tumor volume was calculated using the formula: $\mathrm{V}($ volume $)=\mathrm{L}($ length $) \times \mathrm{W}($ width $) \times \mathrm{H}($ height $) / 2$. The mice were monitored weekly for tumor growth and GPC3_3 aptaprobe using in vivo imaging system (IVIS) imaging as described below.

\subsection{Aptaprobe-based blotting assay: Aptablotting}

The analysis was performed using a previously described protocol with some modifications (Figure 2A) [28]. GPC3 aptaprobes, GPC3_2, GPC3_3, and GPC3_9, were synthesized with 5' biotinylation by IDT. GPC3, HSA, and BSA $(5 \mu \mathrm{g})$ were loaded into each well and $5 \mu \mathrm{g}$ GPC3 was spiked into human serum. All proteins were separated using $10 \%$ SDS-PAGE and transferred to a nitrocellulose (NC) membrane (GE Healthcare). The transferred proteins were stained with a Ponceau S. The membrane was blocked for $1 \mathrm{~h}$ and washed thrice with TBS-T. GPC3 aptaprobes were used to detect only the GPC3 protein. The blocked membranes were incubated with $1 \mu \mathrm{g} \mathrm{mL}^{-1} \mathrm{GPC} 3$ aptamer in blocking buffer for $3 \mathrm{~h}$ at $4^{\circ} \mathrm{C}$ and washed thrice with TBS-T. The GPC3 aptamers were detected using 1:2000 diluted HRP-conjugated streptavidin (Thermo Fisher Scientific) in blocking buffer for $1 \mathrm{~h}$ at $4^{\circ} \mathrm{C}$. The HRP signal was developed using an enhanced chemiluminescence (ECL) system. In aptaprobe-dot blotting, the serially diluted proteins (100, $50,10,1$, and $0 \mathrm{pmol}$ ) were immobilized on $\mathrm{NC}$ membranes using the method mentioned above.

\subsection{Aptaprobe-based quantitative detection of GPC3: Aptaprobe-linked immobilized sorbent assay (ALISA)}

ALISA was performed in streptavidin-coated 96-well plates for quantitative GPC3 protein detection using GPC3 aptamers. Biotinylated GPC3_2 and GPC3_9 aptaprobes $(1 \mu \mathrm{M} /$ well $)$ were used to immobilize a 96well plate for $1 \mathrm{~h}$ at $25^{\circ} \mathrm{C}$. The plate was washed thrice and non-specific binding was blocked with TBS-T containing $2 \%$ BSA. The same concentration $(500 \mathrm{ng} / 100 \mu \mathrm{L})$ of GPC3, GPC5, BSA, and HSA was then added to each well and incubated for $1 \mathrm{~h}$ at $25^{\circ} \mathrm{C}$ with general shaking. Then, 5, 10, 25, 50, 100, 250, and $500 \mathrm{ng} / 100 \mu \mathrm{L}$ GPC3 protein were added to each well. The unbound proteins were discarded and washed thrice with a washing buffer. To quantify the signaling target protein, the FAM-modified aptaprobe GPC3_3 (1 $\mu \mathrm{M} /$ well) was added to individual wells for $30 \mathrm{~min}$ at RT. Following the reaction, the unbound and non-specific bound FAM-modified GPC3_3 aptaprobe was removed and the plate was washed with washing buffer. The fluorescence intensity of each well was then measured at $495 \mathrm{~nm}$ extension wavelength and $520 \mathrm{~nm}$ emission wavelength using a SPECTRAMAX M2e ELISA reader.

\subsection{Aptaprobe-based fluorescence imaging: Aptaoptical imaging}

In vitro aptaprobe targeting

HepG2 cells ( $1.5 \times 10^{5}$ cells/well) were seeded in 6-well plates onto coverslips (Marienfeld Superior). After incubating for $24 \mathrm{~h}$, the cells were incubated with fresh media containing 200 pM FAM-modified GPC3_2, 
GPC3_3, and GPC3_9 aptaprobe separately for $4 \mathrm{~h}$ at $37^{\circ} \mathrm{C}$ in a $5 \% \mathrm{CO}_{2}$ incubator. The cells were washed three times with DPBS to remove the unbound aptamers, fixed with $4 \%$ paraformaldehyde, and stained with 4',6-diamidino-2-phenylindole (DAPI). Coverslips with fixed cells were mounted on glass slides with a mounting solution. Fluorescence images were obtained using a confocal laser scanning microscope (Zeiss, Oberkochen, Germany).

\section{HCC-positive and HCC-negative cell imaging with GPC3_3 aptaprobe}

HCC (HepG2 and Hep3B), pancreatic cancer (PANC-1 and MIA-PaCa-2), and HeLa cell lines $\left(3.0 \times 10^{4}\right.$ cells/well) were cultured in 24 wells onto coverslips. After incubation for $24 \mathrm{~h}$, the cells were incubated with fresh media containing 0-200 pM FAM-modified GPC3_3 aptaprobe for $4 \mathrm{~h}$ at $37^{\circ} \mathrm{C}$ in a $5 \% \mathrm{CO}_{2}$ incubator. Confocal imaging was performed as described above.

In vivo fluorescence imaging of the xenograft tumor. HCC xenograft model mice were imaged in vivo to minimize the expression of fluorescence in the body by fasting for $12 \mathrm{~h}$. The mice were randomly

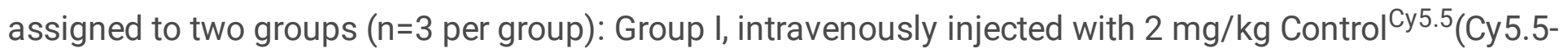

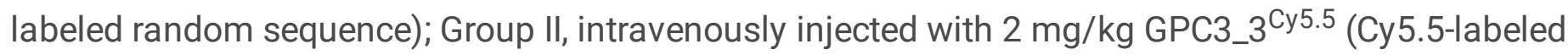
GPC3_3 aptaprobe). The Cy5.5-labeled samples were detected $30 \mathrm{~min}$ after injection by placing the mice in the supine position using the IVIS Lumina system III (Perkin Elmer, Waltham, MA, USA). The mice were euthanized $1 \mathrm{~h}$ after injection, laparotomy was performed, and in situ imaged using Cy5.5 filters, which were normalized to the background signal per manufacturer's protocol. The liver, lung, spleen, kidney, heart, tumor, small intestine, and large intestine tissue of mice were harvested.

\subsection{Statistical analysis}

All statistical analyses were performed using GraphPad Prism or R statistical software [39]. Two-tailed unpaired Student's t-test with Welch correction or one-way analysis of variance were used for multiple comparisons. Statistical significance was defined as $\mathrm{P}<0.05$ in all comparisons and calculated as described in the manuscript or figure legends.

\section{Results And Discussion}

\subsection{Highly specific and efficient GPC3-binding DNA aptamers}

Based on our aptamer screening procedure, specific GPC3 binding aptamers were carefully isolated in this study. Single-strand DNA aptamer candidates against the recombinant GPC3 protein were generated using the modified SELEX protocol [40]. The details of this protocol are available in the Supplementary Information section. The eluted ssDNA concentration in each selection round was monitored using a NanoDrop spectrophotometer, which reflected the binding capacity between the selected ssDNA pool and the GPC3 target. ssDNA concentrations in each round increased until the sixth round of selection (Figure 
S1). Changes in SsDNA concentration indicate that the SsDNA pool was enriched after each selection round. After a negative round, ssDNA aptamer concentrations of the eighth, ninth, and tenth selection rounds were $488.4,491.9$, and $405.9 \mathrm{ng}^{-1} \mathrm{~L}^{-1}$ respectively. At the tenth round, the ssDNA aptamer concentration decreased, suggesting that the ninth round was the optimal state. The GPC3 bound aptamer pool was amplified, cloned, and sequenced. A total of 36 clones were selected for DNA sequencing and 12 different DNA sequences were identified (Table 1).

Table 1

Sequences and affinity value of GPC3 aptamers. Affinity value derived $k a, k d$, and $K_{D}$ values of 12 selected GPC3 aptamers by measuring the surface plasmon resonance (SPR; Biacore X100)

\begin{tabular}{|c|c|c|c|c|}
\hline Clone & Selected Sequence & $\begin{array}{l}k a \\
(1 / \mathrm{Ms})\end{array}$ & $\begin{array}{l}k d \\
(1 / s)\end{array}$ & $K_{D}(\mathrm{M})$ \\
\hline GPC3_1 & CATGATCAATCCCGTACATATTTTATССTCAATTTCACA & $\begin{array}{l}2.09 \times \\
10^{4}\end{array}$ & $\begin{array}{l}6.45 \times \\
10^{-5}\end{array}$ & $\begin{array}{l}3.09 \times \\
10^{-9}\end{array}$ \\
\hline GPC3_2 & ATTTCATAGTGTTCTGTTTTTTTCCAGTTTTCTTATGTCG & $\begin{array}{l}2.28 \times \\
10^{5}\end{array}$ & $\begin{array}{l}9.84 \times \\
10^{-4}\end{array}$ & $\begin{array}{l}4.31 \times \\
10^{-9}\end{array}$ \\
\hline GPC3_3 & СCTATTCCTTATTATATTTTCTTTTTTTGTAATTTGGTCG & $\begin{array}{l}3.67 \times \\
10^{5}\end{array}$ & $\begin{array}{l}4.40 \times \\
10^{-5}\end{array}$ & $\begin{array}{l}1.2 \times \\
10^{-10}\end{array}$ \\
\hline GPC3_4 & CCATAATACTGTTTTTTCCGCTGCTATTAGTTACCTCACG & $\begin{array}{l}1.11 \times \\
10^{4}\end{array}$ & $\begin{array}{l}7.14 \times \\
10^{-5}\end{array}$ & $\begin{array}{l}6.46 \times \\
10^{-9}\end{array}$ \\
\hline GPC3_5 & GCAATCATATGATTTTCCATTACCTCGTTTTTACTTTATT & $\begin{array}{l}2.20 \times \\
10^{5}\end{array}$ & $\begin{array}{l}8.53 \times \\
10^{-4}\end{array}$ & $\begin{array}{l}3.88 \times \\
10^{-9}\end{array}$ \\
\hline GPC3_6 & TAGTTCTTTTAGGGGTTTTTTGTTTGTCTATGTGTTGTGG & $\begin{array}{l}2.00 \times \\
10^{5}\end{array}$ & $\begin{array}{l}1.35 \times \\
10^{-4}\end{array}$ & $\begin{array}{l}6.71 \times \\
10^{-10}\end{array}$ \\
\hline GPC3_7 & ATCTTTTAGTTTGTTTGTATATGTTTTTCTCATTTTCTCG & $\begin{array}{l}5.94 \times \\
10^{3}\end{array}$ & $\begin{array}{l}6.30 \times \\
10^{-5}\end{array}$ & $\begin{array}{l}1.06 \times \\
10^{-8}\end{array}$ \\
\hline GPC3_8 & ATACATTACTATACTGTGCCATTTTTTATATCCGTTCG & $\begin{array}{l}2.75 \times \\
10^{4}\end{array}$ & $\begin{array}{l}5.00 \times \\
10^{-5}\end{array}$ & $\begin{array}{l}1.82 \times \\
10^{-9}\end{array}$ \\
\hline GPC3_9 & ACTTCCTTTTTTTCGTCTTGTTATCGTTTCCTTATTCTCG & $\begin{array}{l}2.5 \times \\
10^{5}\end{array}$ & $\begin{array}{l}5.17 \times \\
10^{-5}\end{array}$ & $\begin{array}{l}2.07 \times \\
10^{-10}\end{array}$ \\
\hline GPC3_10 & TTCTTGTCATAAATATTTCCTATTTCCATTCGTACTCCG & $\begin{array}{l}1.72 \times \\
10^{4}\end{array}$ & $\begin{array}{l}6.12 \times \\
10^{-5}\end{array}$ & $\begin{array}{l}3.57 \times \\
10^{-9}\end{array}$ \\
\hline GPC3_11 & TTTCTTTTGCGTATTATTTACCTTATTTTCTTAGTGTG & $\begin{array}{l}1.80 \times \\
10^{6}\end{array}$ & $\begin{array}{l}9.80 \times \\
10^{-4}\end{array}$ & $\begin{array}{l}5.43 \times \\
10^{-10}\end{array}$ \\
\hline GPC3_12 & CTTTTTTCGTGTTTTTAGCTCTTTCCGAGTCTTTTCGAAC & $\begin{array}{l}1.09 \times \\
10^{6}\end{array}$ & $\begin{array}{l}8.91 \times \\
10^{-4}\end{array}$ & $\begin{array}{l}8.16 \times \\
10^{-10}\end{array}$ \\
\hline
\end{tabular}


To determine the characteristics of GPC3-binding ssDNA aptamer candidates, an SPR assay was used to analyze the specific binding of 12 aptamers with different sequences to GPC3 and determine the binding affinity ( $K_{D}$ values) of the ssDNA aptamer (Supplementary materials). $K_{D}$ values of ssDNA aptamer candidates were measured using BIA evaluation software (GE Healthcare). The results indicated that the $K_{D}$ values of these SSDNA aptamer candidates could be classified into three distinct groups. Of these ssDNA aptamer candidates, GPC3_1-GPC3_12 had low $K_{D}$ values (Table 1 ). The $K_{D}$ values of ssDNA aptamers ranged from $1.2 \times 10^{-10}$ to $1.06 \times 10^{-8} \mathrm{M}$. In addition, the results obtained from SPR confirmed that GPC3_3 had the highest affinity for GPC3 based on $K_{D}$ values $\left(1.2 \times 10^{-10} \mathrm{M}\right)$, which would aid the detection of GPC3 targets.

\subsection{D structure analysis of the molecular interaction between DNA aptamer and GPC3 protein}

The GPC3 protein is a member of the glypican family, which is attached to the cell surface and has a glycosylphosphatidylinositol (GPI) anchor region [41]. The protein comprises two subunits, the $\sim 40 \mathrm{kDa}$ a-subunit (light blue) and the $\sim 30 \mathrm{kDa} \beta$-subunit (deep blue), which is cleaved between Arg358 and Ser359 [42] (Figure S2A and S2B). The GPC3 protein structure was predicted using the Glypican-1 structure model, 4YWT, in SWISS-MODEL by piecewise homology (Figure S2C). The GPC3 protein structure was used to determine the structural interactions with the DNA aptamer. The important GPC3 protein residues are shown in Figure S2B and S2C. The predicted GPC3 model consists of 16 a-helices and three major lobes [43].

These aptamers have complex secondary structures, including protruding loops and stems. The interaction conformation between the GPC3 protein and each aptamer candidate is shown in Figure S3A. The GPC3 protein was fixed in the same position for analysis, and each aptamer binding site of the GPC3 protein is shown in a different color. We also analyzed the detailed GPC3 protein-aptamer binding interaction using COCOMAPS/CONSRank and LigPlot+, and the amino acid sequence of the GPC3 protein is shown in Table S1. We further analyzed the distance of contact sequence between the GPC3 and 12 aptamer candidates, and indicated them using the heatmap; dark purple color indicates $>4 \AA$ distance, while the bright color indicates $<4 \AA$ distance or closer [44] (Figure S3B). All aptamer candidates showed a strong bright color in distinct areas of the GPC3 protein sequences, showing that the interaction between the GPC3 amino acid residues and DNA aptamers is in the proximation position. We analyzed the heatmap to measure the binding distance between the GPC3 amino acid residues. Heatmaps representing intermolecular contacts for individual residues indicated that frequent contact of the GPC3/GPC3_3 aptamer (green) interaction was comparable to that of the GPC3/GPC3_9 aptamer (magenta) interaction. However, the interaction mode of the GPC3/GPC3_2 aptamer (light purple) was completely different from those of the GPC3/GPC3_3 and GPC3/GPC3_9 aptamers (Figure 1A). To characterize the GPC3-DNA aptamer interaction comprehensively, visual contact performances using the COCOMAPS web server were obtained (Figure 1B). Despite the nucleotide sequence differences, two DNA aptamers (GPC3_3 and GPC3_9) bind to GPC3 with similarly. In addition, we studied the relative 
contribution of hydrogen bonds and hydrophobic interactions of GPC3 at the DNA aptamer binding sites. All 12 DNA aptamer candidates were analyzed for hydrogen bonding at the GPC3 binding interface using LigPlot+ software (Table S1). The average distance of the hydrogen bonds is shown in Figure 1C. This result demonstrates that the GPC3_3 aptamer had the shortest distance, which may help stabilize the GPC3 protein-aptamer complex by mediating strong hydrophobic interactions. Hydrophobic interactions can influence binding affinity and molecular functional activity $[45,46]$. These results correspond well with those described in the SPR affinity analysis (Table 1). Based on the GPC3_3 structural interactions, which the binding region is comparable to GPC3_3, and GPC3_2, which is totally different, referred to "Aptaprobes." We then attempted to determine the functional binding of GPC3 aptaprobes (GPC3_3, GPC3_2, and GPC3_9) and confirmed their structure-based functional differences. As shown in Table S1, the results of the structural interaction of the aptaprobes binding with GPC3 protein involves 3D interaction between the binding site on GPC3 and the nucleotide paratopic sequences (nt-paratope), the binding site on the aptaprobes. The binding geometry of GPC3_3 aptaprobes indicated that five ntparatopes (T3, C13, A25, A97, and C99) were responsible for binding to the GPC3 aptatopes: the specific amino acid residues, Lys453, Lys467, and Val532, have a significant interaction with the 5 '-end ntparatope and Asp193 and Cys197 bind with the 3 '-end nt-paratope (Figure 1D). GPC3 consists of an Nterminal secretory signal peptide and a C-terminal core domain. The GPC3 core forms a complex with Wnts, activating downstream signal transduction and stimulating HCC proliferation [47]. GPC3_3 aptaprobes bind directly to the GPC3 core region, suggesting that the aptaprobe may alter the GPC3-Wnt signaling pathway. Since GPC3 expression increases in HCC, aptaprobes can be suggested as potential therapeutics for HCC.

Figure 1E illustrates that the GPC3_2 aptaprobe binds to GPC3 at two binding sites different from GPC3_3 binding sites (Figure 1D). The GPC3_2 aptaprobe comprises two physically connected paratopic moieties (six nt-paratopes of GPC3_3 aptaprobes: T72, T78, T80, A4, A87, and G88) that can simultaneously interact with two different aptatopes, His412, Asn127, Asn124, His121, and Gln106 (Table S1), respectively. On the contrary, GPC3_9 aptaprobe and GPC3 binding are mediated by the interaction of the nt-paratope and aptatope interface, which partially overlap with those of the GPC3_3 aptaprobe (Figure $1 \mathrm{E}$ and F). The three-region nt-paratope of GPC3_9 aptaprobe from nucleotides C62, C93, and A94 generates specific GPC3 binding, corresponding to the aptatopic residues Lys247 and Thr4. In addition, the nt-paratopes A4, C8, C13, and T16, and linear aptatopes, Cys197, Arg199, and Lys347, are linked to each other. In particular, aptatopesLys486 and Asn554 aptatopes in the GPI region of the GPC3 protein interact with $\mathrm{A} 25$ and $\mathrm{A} 30$ nt-paratopes.

Structural analysis of the molecular interaction was performed using MOE-docking-based 3D prediction to determine whether the two aptaprobes occupy distinct GPC3 sites during binding. If an identical binding site is involved, the aptaprobe-GPC3-aptaprobe sandwich configuration would be disturbed. The data on non-ligand residues involved in hydrophobic contact of GPC3 protein-aptaprobe analysis (Table S1) indicate that GPC3_2 and GPC3_3 aptaprobes have different binding sites, while GPC3_9 and GPC3_3 aptaprobes have similar binding sites. Figure S4 depicts the interaction between the GPC3 protein and different aptaprobes (GPC3_3, GPC3_2, and GPC3_9). The GPC3_2 aptamer binds to different 
setsamino acid residues on GPC3 (Figure S4A and S4B), but the GPC3_9 and matchedGPC3_3 aptaprobes bind to 17 common amino acids on GPC3 (Figure S4A and S4C; Met1, Ala2, Leu192, Asp193, Ile194, Glu196, Cys197, Phe445, Pro455, Ser460, Glu490, Leu523, Tyr528, Leu530, Asp531, Asp533, and Asp534). Taken together, GPC3_2 and GPC3_3 were finally chosen for ALISA as capture and reporter, respectively. The results of this study highlight that the molecular docking can successfully predict the interaction between nt-paratopes and aptaprobes, which is promising for high-throughput aptamer screening. We present three GPC3 detection methods using: GPC3_3, GPC3_2, and GPC3_9 aptaprobes.

\subsection{Aptablotting assay for the GPC3-aptaprobe interaction}

The GPC3 protein is gradually expressed in the serum and tissues of HCC patients [48]. Sodium dodecyl sulfate polyacrylamide gel electrophoresis (SDS-PAGE) is the most popular biomarker detection method, which identifies a specific biomarker protein in a complex matrix, such as tissue lysate, blood, or other clinical samples. This motivated us to use aptaprobes for GPC3 detection. Aptablotting has previously showed that the aptamer can help overcome the obstacles of current immunoblot assays [28]. In this study, we designed an aptablot assay for GPC3 detection. GPC3_3, GPC3_2, and GPC3_9 aptaprobes were chosen for establishing an aptablotting assay and chemically synthesized as biotin-labeled affinity aptamers (Figure 2A). Subsequently, we tested whether the aptamers non-specifically react with various proteins, such as serum proteins, human serum albumin (HSA), and bovine serum albumin (BSA). The purified recombinant protein GPC3 was used as a control (Figure 2B). The GPC3 proteins and test samples were separated using $10 \%$ SDS-PAGE and then transferred onto a nitrocellulose (NC) membrane. Following a simple blocking step, the aptablotting assay required only a single aptaprobe affinity detection using each biotinylated aptaprobe. It is important to note that three GPC3 aptaprobes could recognize their target in both SDS-denatured environments and complex biological samples. In contrast, GPC3 aptaprobes did not react with the serum abundant proteins HSA or BSA.

The aptaprobes could recognize GPC3 in its native state. Figure $2 \mathrm{C}$ and Figure S5A show the specificity and sensitivity of the aptamer probe to GPC3 concentration in the dot blot assay. The GPC5 protein, a member of the glypican family protein, is not specific to antibodies and aptaprobes with specificity [49]. When GPC3 was included to represent the complex protein mixture (human serum: $\mathrm{H}$. serum; bovine serum: B. serum), it was clearly demonstrated that the aptamer-bound GPC3 proteins selectively and the observed binding signals were not due to non-specific adsorption to either NC membrane or abundant serum proteins. However, anti-GPC3 antibody showed a strong signal in human serum without GPC3, which was generated by the reaction of human serum with second antibody for detection because the first GPC3 antibody was sourced from humans. Finally, all aptaprobes, GPC3_3, GPC3_2, and GPC3_9, exhibited similar binding behaviors toward native GPC3 proteins. In particular, GPC3_3 aptaprobe reacted with 1 pmol GPC3 in both $\mathrm{H}$. serum and B. serum.

Realizing that the isolated aptaprobes tended to recognize their target structure well in SELEX conditions where they were originally isolated or not, the aptablotting performances in SDS-denatured environment were far from their appropriate condition. Some proteins are known to be resistant to SDS-induced denaturation $[50,51]$. It has been shown that aptamer binding was observed in the SDS-PAGE and 
blotting assays, suggesting that insufficient SDS amount and intrinsic structural rigidity contribute to SDS resistance $[52,53]$. We concluded that the high level of GPC3 structural conservation from SDS denaturation may be used as the basis for the aptablotting assay to identify both SDS-denatured and native GPC3 proteins.

The aptablotting assay can directly detect GPC3, whereas western blotting detection by antibody-based experiments is generally stepwise with incubation and labeling, such as primary and secondary antibody use. In addition, negatively charged nucleic acid aptamers bind poorly to the PVDF/NC membrane, indicating that the aptaprobe-involved aptablotting assay can be improved and contribute to their ability to detect and image targets with various signal read-out fluorescent or colorimetric tags. It is expected that the immunoblotting with primary and secondary antibodies might lead to several non-specific signals in addition to the GPC3 signals (Figure S5B, see red arrow). This means that the GPC3 aptaprobe should not cross-react with non-target molecules in the sample mixture, and our aptablotting protocol simplifies the immunoblotting workflow. To be an effective cellular target binding reagent, an aptaprobe should ideally be achieved following binding to its aptatopes expressed on the cell surface of various cell lines.

\subsection{Quantitative-ALISA platform for detecting GPC3}

Interest in the use of aptamers in ALISA is on the rise [8, 30,35]. ALISA relies on the formation of a sandwich configuration between two layers of the aptaprobe pair (capture and reporter probes), which binds to the target to create a sandwich complex. This indicates that aptaprobes should bind to distinct aptatopes, and their target recognition should not be mutually exclusive. To identify the aptaprobe pair, individual aptatopes should be tested pairwise in a sandwich matrix so that each aptatope is occupied with other candidates, both as capture and reporter aptatopes. However, this conventional method is extremely time-consuming and labor-intensive to complete, and less time-consuming approaches are required. It should be noted here that molecular docking can be considered as a valuable strategy to provide high-quality and functional aptaprobes and contribute to understanding the binding configuration of aptaprobe-target ligands.

ALISA-quantitative detection was performed as shown in the sandwich assay platform, which is easy to use and does not require any coupling of stepwise secondary antibodies for signal readouts (Figure 3 ). To confirm the use of aptaprobe pairs for detecting GPC3 in ALISA, three blanks (C1: microwell plate, C2: non-specific reporter aptaprobe binding, and C3: non-specific target binding without capture aptaprobe), and two negative controls (C4; biotinylated GPC3_9 and fluorescein amidite (FAM)-labeled GPC3_3, and C5; biotinylated GPC3_2 and FAM-labeled GPC3_3) were used. The experimental test groups were set as [Test1] to [Test4] (Figure 3A).

The normal sandwich assay platform was subjected to quantitative analysis after treatment with 5,10 , $25,50,100,250$, and $500 \mathrm{ng}$ in $100 \mu \mathrm{L}$ GPC3 protein. Therefore, the fluorescence signal combined with the reporter aptaprobe was confirmed only in the GPC3_2-GPC3-GPC3_3 configuration condition [Test4]. This is because GPC3_9 and GPC3_3 have the same binding sites in GPC3, which interferes with GPC3 
binding when they were used for the ALISA [Test3]. The blanks, control (C1-C5) and Test1-Test3 groups had no effect on signal response (Figure 3A). Increasing GPC3 concentration increased the signal response, and ALISA demonstrated identified $<1 \mathrm{ng} / \mathrm{mL}$ GPC3 in clinically relevant serum levels. The results of the ALISA followed the linear equation $Y=616.92 \log _{10}(X)-342.75\left(R^{2}=0.9958\right)$ (Figure 3B) and corresponded significantly to the binding interaction results (Figure 3C).

\subsection{Aptaprobe-based fluorescence imaging: Aptaoptical imaging}

GPC3 has three parts: signal peptide for membrane translocation (SP), cysteine-rich domain (CRD), and glycosylphosphatidylinositol (GPI). The Notum cleavage site breaks the bond between amino acids 562 and 563 [47], causing proteins other than GPI to be secreted into the serum (Figure S2). FAM-labeled GPC3_3 and GPC3_2 aptaprobes successfully achieved targeted imaging in HepG2 cells, which are known to overexpress GPC3 protein on their cytoplasmic membrane (Figure 4). However, HepG2 cells were incubated with the FAM-labeled GPC3_9 aptaprobe and confocal imaging results demonstrated that the fluorescence signal was reduced (Figure S6). This may be due to the non-binding of the GPC3_9 aptaprobes that did not bind to their potential binding site (GPI site, Table S1) by the cell membranebound region. However, FAM-labeled GPC3_3 and GPC3_2 aptamers successfully achieved targeted imaging in HepG2. FACS experiments supporting the results of confocal imaging, blocked GPC3_9 aptaprobe binding. This is consistent with the results of previous confocal imaging experiments (Figure 4). As mentioned earlier, GPC3 is a heparan sulfate proteoglycan, and the relationship between protein glycosylation alteration and liver diseases has been reported [54]. Our GPC3_3 aptaprobes may be used to monitor glycosylation alterations during HCC progression.

The aptaprobe-binding capacity can be maintained within the actual cellular environment. We used two pancreatic cancer cells, PANC-1 and MIA-PaCa, as negative controls for aptamer binding, as these cells do not express GPC3. To confirm GPC3 expression, the mRNA expression levels were determined preferentially. GPC3 gene expression was observed in only two HCC cell lines, HepG2 and Hep3B, but not in the pancreatic cancer cells (Figure S7). To verify extracellular GPC3 targeting, GPC3-positive and negative cell lines were incubated at $37^{\circ} \mathrm{C}$ for $30 \mathrm{~min}$ with FAM-labeled GPC3_3 aptaprobes. An intense fluorescent signal was observed in GPC3-positive cells, indicating that GPC3_3 aptamers specifically targeted the surface of the liver cancer cell membrane. FACS experiment using FAM-modified aptamers confirmed the result of confocal imaging. A shift ratio of $<1 \%$ was observed in the GPC3-negative cell lines (HeLa, PANC-1, and MIA-PaCa), while a shift ratio of approximately $99 \%$ was observed in the GPC3 positive cell lines (HepG2 and Hep3B) (Figure 5). These results indicate that the aptaprobe can distinguish the GPC-3 positive cancer cell lines from the GPC-3 negative-cell lines. Chemical modifications (Cy3 and FAM) are beneficial for applications in HCC imaging. In the 3-(4,5-dimethylthiazol2-yl)-2,5-diphenyl tetrazolium bromide salt (MTT) assay, HepG2 cells incubated with GPC3_3 aptaprobes retained their high survival properties, indicating the low cytotoxicity of GPC3_3 aptaprobes (Figure S8A). Corresponding to confocal imaging, the HepG2 cells did not show any nuclear or cytoplasmic morphological changes. Additionally, the intracellular metabolic potential and mitochondrial respiration 
of the aptaprobe were confirmed. Since at least $90 \%$ cellular energy is produced by mitochondria, we investigated whether the aptaprobe affects mitochondrial structure, which reflects a disruption in cellular bioenergetics. We utilized the Seahorse XF analyzer mito stress test, which allows the real-time measurement of both extracellular acidification rate (ECAR), a measure of glycolysis, and oxygen consumption rate (OCR), a measure of oxidative phosphorylation $[55,56]$. A $1 \mathrm{~h}$ treatment with 0.15 to 10 MM GPC3_3 aptaprobe slightly increased baseline OCR than that in the control, and no difference in baseline ECAR (Figure S8B and S8C). The $10 \mu \mathrm{M}$ aptaprobe concentration did not affect toxicity, cytoplasmic morphology, or mitochondrial respiration. Taken together, the aptaprobe has low (or no) cytotoxicity and can be used in various in vitro and in vivo bio-imaging experiments.

Finally, we tested the ability of the GPC3_3 aptaprobe to bind GPC3-expressing tumor in HCC xenograft models in vivo. We established HCC xenograft tumors grown subcutaneously in BALB/c nude mice (Figure S9). To avoid the overlay between the tumor and other tissues in fluorescence imaging, an approximately $169.76 \mathrm{~mm}^{3}$ tumor was successfully induced between the right flank and thigh (data not shown). To confirm that the GPC3_3 aptaprobe targets the target GPC3 protein in vivo, the GPC3_3 aptaprobe and the same size of the random sequence was labeled at the 5 ' end with Cy 5.5 fluorescence and intravenously injected to measure the fluorescence distribution. The retention of the Cy5.5 signal was assessed using the IVIS system. We examined GPC3_3 aptaprobe binding to induce tumor intravenous injection. Figure 6A shows the fluorescence image of Balb/c nude mice bearing subcutaneous HCC tumors after intravenous injection of Control ${ }^{\mathrm{Cy} 5.5}$ and GPC3_3 $3^{\mathrm{Cy} 5.5}$. All injected formulations were imaged immediately after injection, indicating the whole body through blood circulation after intravenous injection. The GPC3_3 ${ }^{\text {Cy5.5 }}$ signal shifted to the right flank and thigh, where the induced tumor was localized. The fluorescence signal intensity of normalized tumor area with GPC3_3 ${ }^{\text {Cy5.5 }}$ was significantly higher than that of Control ${ }^{\text {Cy5.5 }}$ signal $\left(1.4 \times 10^{9}\right.$ vs $2.89 \times 10^{9}$ counts; $P=0.002$; Figure $\left.6 \mathrm{~B}\right)$. Then, ex vivo fluorescence imaging was conducted to examine the biodistribution profile $1 \mathrm{~h}$ post injection. We found that the fluorescence signal was also observed in the tumor tissue of the GPC3_3 ${ }^{\text {Cy5.5 }}$ injected mice group, but no Control ${ }^{\mathrm{Cy} 5.5}$ signal was not observed in the control group (Figure 6C). This indicates that the GPC3_3 aptaprobe, which has high affinity and specificity to the GPC3 protein, is quickly distributed and targeted to HCC tumor tissue. This verifies that the aptaprobe can have high specificity and discriminate the target protein in complex biological samples. In addition to tumor sites, the GPC3_3 aptaprobe (as indicated by fluorescence) was mainly distributed in the liver and kidney (Figure S10), consistent with the biodistribution data of Control ${ }^{\mathrm{Cy} 5.5}$ [57-59]. It should be emphasized that the relatively weak fluorescence of GPC3_3 ${ }^{\text {Cy5.5 }}$ aptaprobe in the tumor fluorescence image might be due to fluorescence quenching by in vivo biomolecules because the tumors were isolated $>1 \mathrm{~h}$ after the injection of GPC3_3 ${ }^{\text {Cy5.5}}$ aptaprobe. After intravenous injection of GPC3_3 ${ }^{\mathrm{Cy} 5.5}$ aptaprobe, the signal in the tumor region dramatically increased, leading to the visualization of the tumor at $1 \mathrm{~h}$ post injection (Figure 6A). The fluorescence signal of the aptaprobe in the tumor region appears faster than that in the in vivo imaging experiment using other materials; such nanoparticles appeared within $72 \mathrm{~h}$, and biological molecules (peptides and aptamers) were observed within 1 to $2 \mathrm{~h}$ (Table S2). This should be mainly attributed to the fact that 
fluorescence signal imaging usually relies on in vivo experimental conditions. These data highlight that aptaprobe-based fluorescence imaging allows fast detection of tumors with high specificity and targeting over other materials.

\section{Conclusion}

GPC3 is a promising biomarker for early HCC diagnosis. Aptaprobes were successfully isolated using the SELEX methodology, and their binding moieties were predicted through MOE docking analysis. To explore the potential use of GPC3 aptamers in HCC diagnosis, Aptablotting, ALISA, and intra-/extracellular GPC3 imaging were performed. Aptaprobes do not cross-react with non-target molecules in a complex biological mixture, and aptablotting undoubtedly simplifies the immunoblotting workflow. Here, we showed through structure-based molecular interaction that aptaprobe pairs are significant for designing quantitative ALISA platforms. FAM-labeled GPC3_3 aptaprobes were successfully used to fluorescent stain HeLa, HepG2, Hep3B, PANC-1, and MIA-PaCa cells, which will provide insight into the development of aptaprobe-based atopic imaging diagnosis technology. Our GPC3 aptaprobe can potentially be used as an affinity reagent to detect in vivo and in vitro GPC3 diagnosing systems such as Aptablotting, ALISA, and Aptaoptical imaging. Therefore, it is reasonable to speculate that our aptaprobe strategy might be useful in HCC diagnosis.

\section{Declarations}

\section{CRediT authorship contribution statement}

Y.H.K., J.Y.A., and J.M. conceived the project. W.R.S. and D.Y.P performed the experiments with help from J.H.K., J.P.L., N.Q.T., I.H.O., and W.C. All authors wrote the manuscript with help from S.S.S., S.Y.K., B.K.C., and S.C.K.

\section{Data availability}

Research data refers to the results of observations or experimentation that validate research findings. Data includes "raw" data and processed data.

Ethics approval and consent to participate Not applicable.

Conflict of interest The authors declare no conflict of interest.

Consent for publication Not applicable.

\section{Acknowledgements}

The research was funded, in part, by the National Research Foundation of Korea (NRF) (NRF2020R1A2C1009463 and 2020R1A6A1A06046235). 


\section{References}

1. Hassanipour-Azgomi S, Mohammadian-Hafshejani A, Ghoncheh M, Towhidi F, Jamehshorani S, Salehiniya $\mathrm{H}$. Incidence and mortality of prostate cancer and their relationship with the Human Development Index worldwide. Prostate international. 2016;4:118-24.

2. Ringelhan M, Pfister D, O'Connor T, Pikarsky E, Heikenwalder M. The immunology of hepatocellular carcinoma. Nature immunology. 2018;19:222-32.

3. Golabi P, Rhea L, Henry L, Younossi ZM. Hepatocellular carcinoma and non-alcoholic fatty liver disease. Hepatology international. 2019;13:688-94.

4. Mittal S, El-Serag HB. Epidemiology of HCC: consider the population. Journal of clinical gastroenterology. 2013;47:2.

5. Ferenci P, Fried M, Labrecque D, Bruix J, Sherman M, Omata M, Heathcote J, Piratsivuth T, Kew M, Otegbayo JA. Hepatocellular carcinoma (HCC): a global perspective. Journal of clinical gastroenterology. 2010;44:239-45.

6. Kee K-M, Lu S-N. Diagnostic efficacy of ultrasound in hepatocellular carcinoma diagnosis. Taylor \& Francis; 2017.

7. Zhang W, Wang X, Huang R, Jin K, Zhangyuan G, Yu W, Yin Y, Wang H, Xu Z, Sun B. Prognostic value of marital status on stage at diagnosis in hepatocellular carcinoma. Scientific reports. 2017;7:41695.

8. Lee K-A, Ahn J-Y, Lee S-H, Sekhon SS, Kim D-G, Min J, Kim Y-H. Aptamer-based sandwich assay and its clinical outlooks for detecting lipocalin-2 in hepatocellular carcinoma (HCC). Scientific reports. 2015;5:10897.

9. Choi J, Kim GA, Han S, Lee W, Chun S, Lim YS. Longitudinal assessment of three serum biomarkers to detect very early-stage hepatocellular carcinoma. Hepatology. 2019;69:1983-94.

10. Galle PR, Foerster F, Kudo M, Chan SL, Llovet JM, Qin S, Schelman WR, Chintharlapalli S, Abada PB, Sherman M. Biology and significance of alpha-fetoprotein in hepatocellular carcinoma. Liver international. 2019;39:2214-29.

11. Javadpour N. Significance of elevated serum alphafetoprotein (AFP) in seminoma. Cancer. 1980;45:2166-8.

12. Stafylidou M, Paschos P, Katsoula A, Malandris K, loakim K, Bekiari E, Haidich A-B, Akriviadis E, Tsapas A: Performance of Baveno VI and expanded Baveno VI criteria for excluding high-risk varices in patients with chronic liver diseases: a systematic review and meta-analysis. Clinical Gastroenterology and Hepatology 2019, 17:1744-1755. e1711.

13. Xu R-h, Wei W, Krawczyk M, Wang W, Luo H, Flagg K, Yi S, Shi W, Quan Q, Li K. Circulating tumour DNA methylation markers for diagnosis and prognosis of hepatocellular carcinoma. Nat Mater. 2017;16:1155-61.

14. Hassan N, Greve B, Espinoza-Sánchez NA, Götte M. Cell-surface heparan sulfate proteoglycans as multifunctional integrators of signaling in cancer. Cellular Signalling 2020:109822. 
15. Nishio T, Koyama Y, Liu X, Rosenthal SB, Yamamoto G, Fuji H, Baglieri J, Li N, Brenner LN, Iwaisako K: Immunotherapy-based targeting of MSLN+ activated portal fibroblasts is a strategy for treatment of cholestatic liver fibrosis. Proceedings of the National Academy of Sciences 2021, 118.

16. Li N, Gao W, Zhang Y-F, Ho M. Glypicans as cancer therapeutic targets. Trends in cancer. 2018;4:741-54.

17. Kolluri A, Ho M. The role of glypican-3 in regulating Wnt, YAP, and hedgehog in liver cancer. Frontiers in oncology. 2019;9:708.

18. Yamauchi N, Watanabe A, Hishinuma M, Ohashi K-i, Midorikawa Y, Morishita Y, Niki T, Shibahara J, Mori M, Makuuchi M. The glypican 3 oncofetal protein is a promising diagnostic marker for hepatocellular carcinoma. Modern pathology. 2005;18:1591-8.

19. Nishida T, Kataoka H. Glypican 3-targeted therapy in hepatocellular carcinoma. Cancers. 2019;11:1339.

20. Wang W, Xu C, Wang H, Jiang C. Identification of nanobodies against hepatocellular carcinoma marker glypican-3. Mol Immunol. 2021;131:13-22.

21. Xu H, Tang Y, Zhao Y, Wang F, Gao X, Deng D, Gu Y. SPECT Imaging of Hepatocellular Carcinoma Detection by the GPC3 Receptor. Mol Pharm. 2021;18:2082-90.

22. Zhang Q, Han Z, Tao J, Zhao M, Zhang W, Li P, Tang L, Gu Y. An innovative peptide with high affinity to GPC3 for hepatocellular carcinoma diagnosis. Biomaterials science. 2019;7:159-67.

23. Tangkijvanich P, Chanmee T, Komtong S, Mahachai V, Wisedopas N, Pothacharoen P, Kongtawelert P. Diagnostic role of serum glypican-3 in differentiating hepatocellular carcinoma from non-malignant chronic liver disease and other liver cancers. Journal of gastroenterology hepatology. 2010;25:12937.

24. Li Y-C, Yang C-S, Zhou W-L, Li H-S, Han Y-J, Wang Q-S, Wu H-B. Low glucose metabolism in hepatocellular carcinoma with GPC3 expression. World journal of gastroenterology. 2018;24:494.

25. Jia X, Liu J, Gao Y, Huang Y, Du Z. Diagnosis accuracy of serum glypican-3 in patients with hepatocellular carcinoma: a systematic review with meta-analysis. Arch Med Res. 2014;45:580-8.

26. Lu S-X, Huang Y-H, Liu L-L, Zhang CZ, Yang X, Yang Y-Z, Shao C-K, Li J-M, Xie D, Zhang X. aFetoprotein mRNA in situ hybridisation is a highly specific marker of hepatocellular carcinoma: a multi-centre study. British journal of cancer. 2021;124:1988-96.

27. Shin W-R, Sekhon SS, Rhee S-K, Ko JH, Ahn J-Y, Min J, Kim Y-H. Aptamer-based paper strip sensor for detecting Vibrio fischeri. ACS combinatorial science. 2018;20:261-8.

28. Sekhon SS, Um H-J, Shin W-R, Lee S-H, Min J, Ahn J-Y, Kim Y-H. Aptabody-aptatope interactions in aptablotting assays. Nanoscale. 2017;9:7464-75.

29. Oh I-H, Park D-Y, Cha J-M, Shin W-R, Kim JH, Kim SC, Cho B-K, Ahn J-Y, Kim Y-H. Docking Simulation and Sandwich Assay for Aptamer-Based Botulinum Neurotoxin Type C Detection. Biosensors. 2020;10:98. 
30. Lee S-H, Ahn J-Y, Lee K-A, Um H-J, Sekhon SS, Park TS, Min J, Kim Y-H. Analytical bioconjugates, aptamers, enable specific quantitative detection of Listeria monocytogenes. Biosensors Bioelectronics. 2015;68:272-80.

31. Hu B, Zhou R, Li Z, Ouyang S, Li Z, Hu W, Wang L, Jiao B. Study of the binding mechanism of aptamer to palytoxin by docking and molecular simulation. Scientific reports. 2019;9:1-11.

32. Takahashi M, Amano R, Ozawa M, Martinez A, Akita K, Nakamura Y: Nucleic acid ligands act as a PAM and agonist depending on the intrinsic ligand binding state of P2RY2. Proceedings of the National Academy of Sciences 2021, 118.

33. Kalra P, Dhiman A, Cho WC, Bruno JG, Sharma TK. Simple methods and rational design for enhancing aptamer sensitivity and specificity. Frontiers in molecular biosciences. 2018;5:41.

34. Zuker M. Mfold web server for nucleic acid folding and hybridization prediction. Nucleic acids research. 2003;31:3406-15.

35. Shin W-R, Sekhon SS, Kim S-G, Rhee SJ, Yang GN, Won K, Rhee S-K, Ryu H, Kim K, Min J. Aptamerbased pathogen monitoring for Salmonella enterica ser. Typhimurium. J Biomed Nanotechnol. 2018;14:1992-2002.

36. Rabal O, Pastor F, Villanueva H, Soldevilla MM, Hervas-Stubbs S, Oyarzabal J. In Silico Aptamer Docking Studies: From a Retrospective Validation to a Prospective Case Study'TIM3 Aptamers Binding. Molecular Therapy-Nucleic Acids. 2016;5:e376.

37. Vangone A, Spinelli R, Scarano V, Cavallo L, Oliva R. COCOMAPS: a web application to analyze and visualize contacts at the interface of biomolecular complexes. Bioinformatics. 2011;27:2915-6.

38. Laskowski RA, Swindells MB. LigPlot+: multiple ligand-protein interaction diagrams for drug discovery. ACS Publications; 2011.

39. Team RC. R: a language and environment for statistical computing. R Foundation for Statistical Computing, Vienna. http s. wwW R-proje ct org 2018.

40. Bayat P, Nosrati R, Alibolandi M, Rafatpanah H, Abnous K, Khedri M, Ramezani M. SELEX methods on the road to protein targeting with nucleic acid aptamers. Biochimie. 2018;154:132-55.

41. Ho M, Kim H. Glypican-3: a new target for cancer immunotherapy. European journal of cancer. 2011;47:333-8.

42. Guo M, Zhang H, Zheng J, Liu Y: Glypican-3: A New Target for Diagnosis and Treatment of Hepatocellular Carcinoma. Journal of Cancer 2020, 11:2008.

43. Li N, Wei L, Liu X, Bai H, Ye Y, Li D, Li N, Baxa U, Wang Q, Lv L. A Frizzled-Like Cysteine-Rich Domain in Glypican-3 Mediates Wnt Binding and Regulates Hepatocellular Carcinoma Tumor Growth in Mice. Hepatology. 2019;70:1231-45.

44. Esmaielbeiki R, Krawczyk K, Knapp B, Nebel J-C, Deane CM. Progress and challenges in predicting protein interfaces. Brief Bioinform. 2016;17:117-31.

45. Chen D, Oezguen N, Urvil P, Ferguson C, Dann SM, Savidge TC. Regulation of protein-ligand binding affinity by hydrogen bond pairing. Sci Adv. 2016;2:e1501240. 
46. Patil R, Das S, Stanley A, Yadav L, Sudhakar A, Varma AK. Optimized hydrophobic interactions and hydrogen bonding at the target-ligand interface leads the pathways of drug-designing. PloS one. 2010;5:e12029.

47. Poulain FE, Yost HJ. Heparan sulfate proteoglycans: a sugar code for vertebrate development? Development 2015, 142:3456-3467.

48. Liu H, Li P, Zhai Y, Qu C-F, Zhang L-J, Tan Y-F, Li N, Ding H-G. Diagnostic value of glypican-3 in serum and liver for primary hepatocellular carcinoma. World journal of gastroenterology: WJG. 2010;16:4410.

49. Li F, Shi W, Capurro M, Filmus J. Glypican-5 stimulates rhabdomyosarcoma cell proliferation by activating Hedgehog signaling. J Cell Biol. 2011;192:691-704.

50. Manning M, Colón W. Structural basis of protein kinetic stability: resistance to sodium dodecyl sulfate suggests a central role for rigidity and a bias toward $\beta$-sheet structure. Biochemistry. 2004;43:11248-54.

51. Jafari M, Mehrnejad F, Rahimi F, Asghari SM. The molecular basis of the sodium dodecyl sulfate effect on human ubiquitin structure: a molecular dynamics simulation study. Scientific reports. 2018;8:1-15.

52. Shin S, Kim I-H, Kang W, Yang JK, Hah SS. An alternative to Western blot analysis using RNA aptamer-functionalized quantum dots. Bioorg Med Chem Lett. 2010;20:3322-5.

53. Wang Y, Li Z, Yu H. Aptamer-based Western blot for selective protein recognition. Frontiers in chemistry 2020, 8.

54. Midorikawa Y, Ishikawa S, Iwanari H, Imamura T, Sakamoto H, Miyazono K, Kodama T, Makuuchi M, Aburatani H. Glypican-3, overexpressed in hepatocellular carcinoma, modulates FGF2 and BMP-7 signaling. International journal of cancer. 2003;103:455-65.

55. Plitzko B, Loesgen S. Measurement of oxygen consumption rate (OCR) and extracellular acidification rate (ECAR) in culture cells for assessment of the energy metabolism. Bio-protocol. 2018;8:e2850-0.

56. Nicholas D, Proctor EA, Raval FM, Ip BC, Habib C, Ritou E, Grammatopoulos TN, Steenkamp D, Dooms $\mathrm{H}$, Apovian CM. Advances in the quantification of mitochondrial function in primary human immune cells through extracellular flux analysis. PLoS One. 2017;12:e0170975.

57. Coomber D. Radiochemical methods in analysis. Springer Science \& Business Media; 2012.

58. Alric C, Miladi I, Kryza D, Taleb J, Lux F, Bazzi R, Billotey C, Janier M, Perriat P, Roux S. The biodistribution of gold nanoparticles designed for renal clearance. Nanoscale. 2013;5:5930-9.

59. Zhang Y, Bradshaw-Pierce EL, DeLille A, Gustafson DL, Anchordoquy TJ. In vivo comparative study of lipid/DNA complexes with different in vitro serum stability: effects on biodistribution and tumor accumulation. Journal of pharmaceutical sciences. 2008;97:237-50.

\section{Scheme}

Scheme 1 is available in supplementary section. 


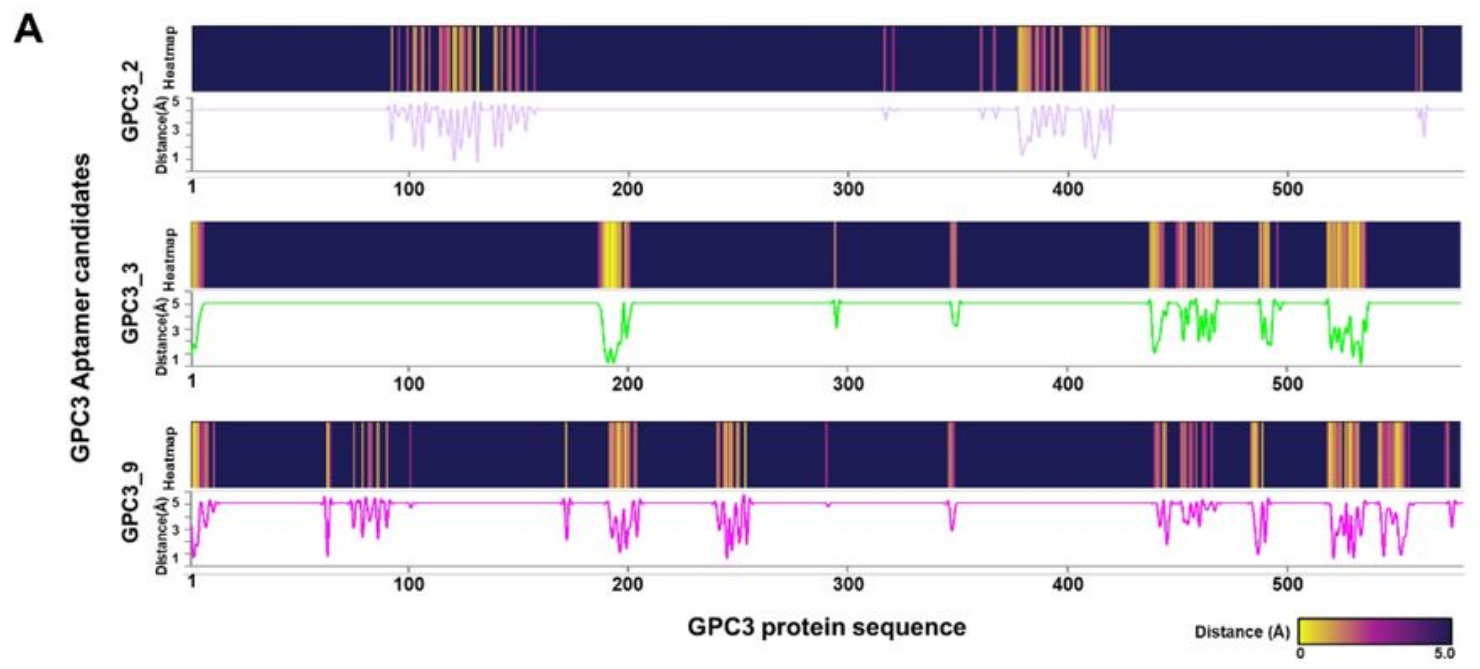

B

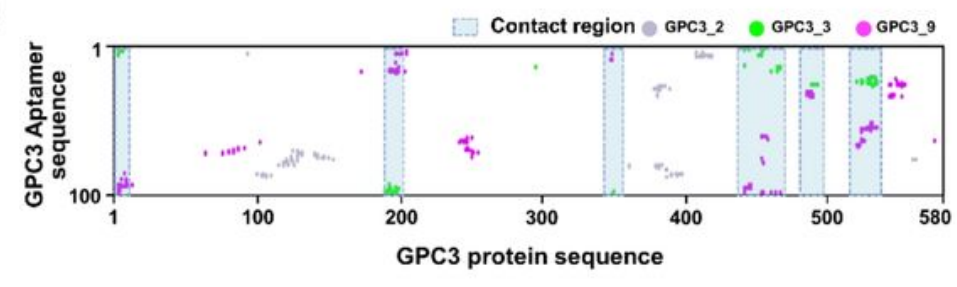

C

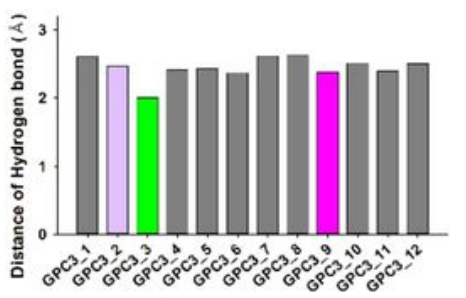

D
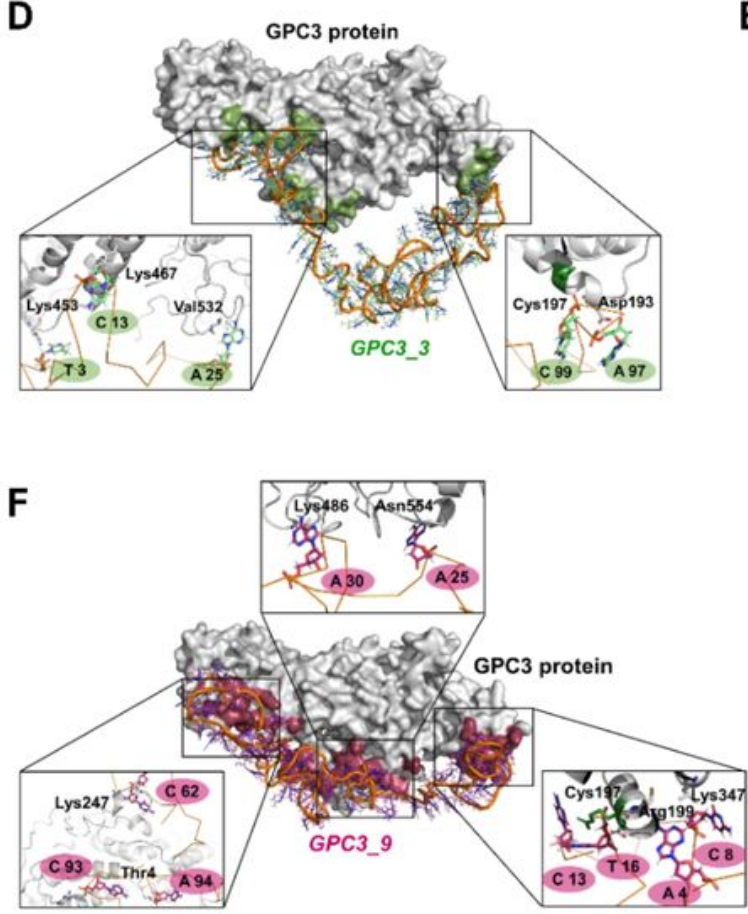

E
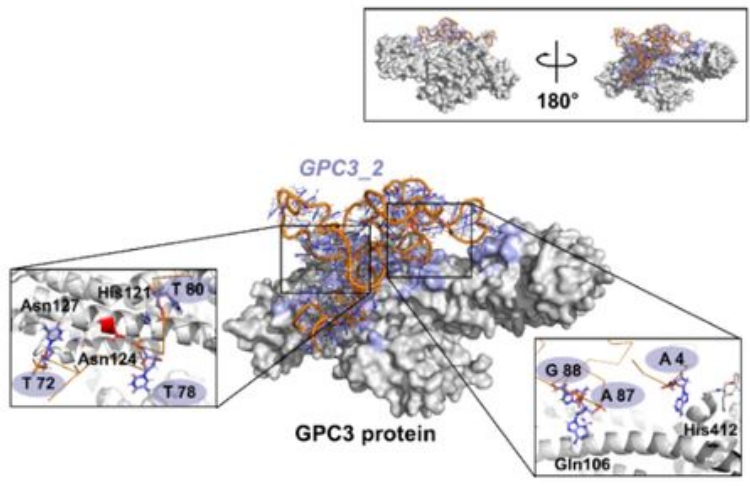

Figure 1

Interaction of the GPC3_3, GPC3_2, and GPC3_9 aptamers with GPC3 protein. (A) Heatmap and graph of the binding distance between GPC3 amino acids and GPC3_3, GPC3_2 and GPC3_9 aptamers. Dark purple color indicates $>4 \AA$ distance, while the bright color indicates $<4 \AA$ distance or closer. (B) GPC3 
protein-aptamer contact map obtained by COCOMAPS. A significant contact region of GPC3 proteinDNA aptamers (GPC3_3, GPC3_2, and GPC3_9) are shown in light purple, green, and magenta, respectively. Six regions in overlapped area of aptamer (GPC3_3 and GPC3_9) have been highlighted through blue rectangles. (C) Average distance of hydrogen bond $(\mathrm{O}-\mathrm{H})$ length $(\AA)$ between GPC3 protein and each DNA aptamer candidate (GPC3_1-GPC3_12). Each value of 12 DNA aptamer candidates was calculated by COCOMAPS/CONSRank and LigPlot+ (see Materials and Methods). The GPC3 protein is depicted as a ribbon structure with stick structure of (D) GPC3_3 (green), (E) GPC3_2 (light purple), and (F) GPC3_9 (magenta). Each color represents areas in GPC3 protein contacted by nt-paratopes.

\section{Figure 2}

Comparative analysis of GPC3 detection with GPC3_3, GPC3_2, and GPC3_9 aptaprobes. (A) Illustration of aptaprobe-based aptablotting. (B) Aptablotting assay of GPC3 protein (lane 1), GPC3 protein spiked in human serum (lane 2), human serum albumin (HSA, lane 3), and bovine serum albumin (BSA, lane 4). (C) Aptaprobe-dot blotting assay showing respective signaling of antibody and aptaprobes to GPC3, GPC5, H.serum+GPC3 and B.serum+GPC3. GPC3 and GPC5 were serially diluted (100, 50, 10, 1, and 0 pmol) and mixed with $10 \mu \mathrm{g}$ human/bovine serum. H.serum: human serum; B.serum: bovine serum.

\section{Figure 3}

Quantitative aptaprobe-based sandwich assay (ALISA) for detecting GPC3. (A) Schematic overview of the GPC3 ALISA platform. The graph is shown for the ALISA combination in the panel as detection GPC3. C1, microwell plate; $\mathrm{C} 2$, non-specific binging of reporter aptaprobes; $\mathrm{C} 3$, non-specific target binding without capture aptaprobe; and two negative controls-C4, biotinylated GPC3_9 and fluorescein amidite (FAM)labeled GPC3_3; and C5, biotinylated GPC3_2 and FAM-labeled GPC3_3. The sandwich ALISA [Test4] quantify GPC3 between two layers of aptaprobes (capture and detection aptaprobes, GPC3_2 and GPC3_3, respectively). [Test3] did not show the fluorescence signal as the immobilized GPC3_9 interrupt the signaled GPC3_3, due to the same binding site. (B) Linear regression of the GPC3 ALISA. All experiments were performed in triplicate. (C) 3D structure two aptaprobes (biotinylated GPC3_2 and FAMlabeled GPC3_3) bind to GPC3 simultaneously and without interference from each other, indicating recognition of distinct aptatope regions.

\section{Figure 4}

Confocal imaging and flow cytometry with GPC3 aptaprobes. Fluorescence image of HepG2 cells using fluorescein amidite (FAM)-labeled GPC3 aptaprobe (GPC3_3, GPC3_2, and GPC3_9). Signals were 
observed on the cytoplasmic membrane on HepG2 cells. Flow cytometry assays of the binding of individual FAM-labeled aptaprobes with HepG2 cells (target cells). Only HepG2 cell is shown in red and each aptaprobe-bound HepG2 is shown with colored green curves.

\section{Figure 5}

Confirmation of the specificity of the immunohistochemistry of GPC3_3 aptaprobe using cancer cell lines. (A) Fluorescence microscopy images of fluorescein amidite (FAM)-GPC3_3 aptaprobe binding to GPC3expressing cells. FAM-GPC3_3 aptaprobe population (green) has been incubated with different cell lines (top to down: Hela cells, HepG2, Hep3B, PANC-1, and MIA-PaCa). Nuclear counter stain was used as a control (blue 4',6-diamidino-2-phenylindole [DAPI] staining). The cells were treated with 0, 50, 100, and 200 pM FAM-modified GPC3_3 aptaprobe. Both DAPI and FAM fluorescence are only shown in HepG2 and Hep3B cells. (B) The flow cytometry results for evaluating GPC3 aptaprobe binding specificity using 200 pM FAM-modified GPC3_3 aptaprobe and the five different cells used for flow cytometry. The flow cytometry results of cells not treated with aptamer (red) and cells treated with aptamer (green) were expressed by overlapping in one diagram. As with the confocal imaging results, the FAM signal appeared only in HepG2 and Hep3B cells.

\section{Figure 6}

\section{Representative imaging of in vivo monitored the hepatocellular carcinoma (HCC) tumor by GPC3_3} aptaprobe. (A) In vivo fluorescence imaging of subcutaneous HCC-bearing mice after intravenous injection of Control ${ }^{\mathrm{Cy}} 5.5$ and GPC3_3 ${ }^{\mathrm{Cy} 5.5}$. The color scales show total fluorescence signal values ranging from $0.4 \times 10^{9}$ (blue) to $5.0 \times 10^{9}$ (red). Tumors are indicated by red spot. (B) Cy.5-labeled control and GPC3_3 aptaprobe fluorescence intensity normalized to tumor area for comparison of in vivo labeled HCC xenograft model ( $P$ value by Welch's t-test). (C) Imaging of Control ${ }^{\text {Cy5.5 }}$ and GPC3_3 ${ }^{\text {Cy5.5 }}$ injected tumor tissue in sacrificed HCC mice with increased fluorescence sensitivity. The color scales show total fluorescence signal values ranging from $0.3 \times 10^{9}$ (red) to $2.5 \times 10^{9}$ (yellow).

\section{Supplementary Files}

This is a list of supplementary files associated with this preprint. Click to download.

- SupplementaryGPC3.docx

- GraphicalAbstract.png

- floatimage1.png 